\title{
Scleral Dellen after Routine Uneventful Pterygium Surgery
}

\author{
Shubhangi Prakash Nagpure ${ }^{1}$, Vishal Keshavrao Wagh ${ }^{2}$ \\ ${ }^{1}$ Department of Ophthalmology, Datta Meghe Institute of Medical Sciences, Wardha, Maharashtra, India. \\ ${ }^{2}$ Department of Ophthalmology, Datta Meghe Institute of Medical Sciences, Wardha, Maharashtra, India.
}

\section{INTRODUCTION}

Occurrence of Scleral Dellen is rare but serious complication with stromal inflammation with tissue loss and scarring. Scleral dellen results from local dehydration \& thinning of scleral tissues with exposure of underlying uvea leading to blueish colour. Occular surgical causes of occurrence of scleral dellen are strabismus surgery, pterygium excision (with or without use of adjunctive treatment like beta radiation, conjunctival autograft and Mitomycin C), cataract extraction. ${ }^{1,2}$ Patients complain of foreign body sensation \& mild discomfort. Treatment consists of reduction or elimination of contributing perilimbal elevation, \& rapid rehydration with artificial tears, eye ointment and patching 3 . If treated properly dellen usually resolves completely without permanent sequelae. We report a case of severe scleral dellen that occurred 14 days after the uneventful surgical excision of primary pterygium without adjuvant therapy. We describe a patient with scleral dellen, which occurred after an uneventful pterygium excision without adjunctive therapy.

\section{PRESENTATION OF CASE}

The patient came to ophthalmology OPD with history of recurrent redness, itching, lacrimation, foreign body sensation \& fleshy mass in her left eye. She also had difficulty in vision in her day to day sewing activity. Ocular examination revealed presence of nasal pterygium which was vascular \& progressive, measuring $3 \mathrm{~mm}$ at the limbus and extending $3 \mathrm{~mm}$ into the cornea. Slit lamp examination was normal \& there was no clinical evidence of dry eye, as Schirmer test was performed without anaesthesia \& results were $15 \mathrm{~mm}$ left eye with a tear film breakup time of 15 seconds. No significant findings were observed in posterior segment.

The pterygium excision was done under topical anaesthesia with $4 \%$ lignocaine along with subconjunctival infiltration of $2 \%$ lignocaine. The head was separated at the limbus \& then lifted off the corneal surface by blunt dissection. After excising the head and the body of pterygium a conjunctival suture was made leaving $3 \mathrm{~mm}$ of bare sclera. At the end of surgery, patient was given combination therapy with Dexamethasone eyedrop $0.1 \%$ \& Moxifloxacin $0.5 \%$ eye ointment was put followed by patching of left eye.
Corresponding Author: Dr. Shubhangi Prakash Nagpure, Senior Resident, Department of Ophthalmology, Datta Meghe Institute of Medical Sciences, Wardha, Maharashtra, India. E-mail: shubhangi.pnagpure@gmail.com

DOI: $10.14260 / \mathrm{jemds} / 2020 / 420$

Financial or Other Competing Interests: None.

How to Cite This Article:

Nagpure SP, Wagh VK. Scleral dellen after routine uneventful pterygium surgery. J. Evolution Med. Dent. Sci. 2020;9(26):19351937, DOI: 10.14260/jemds/2020/420

Submission 16-04-2020, Peer Review 01-06-2020, Acceptance 08-06-2020, Published 29-06-2020.

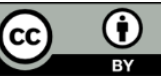



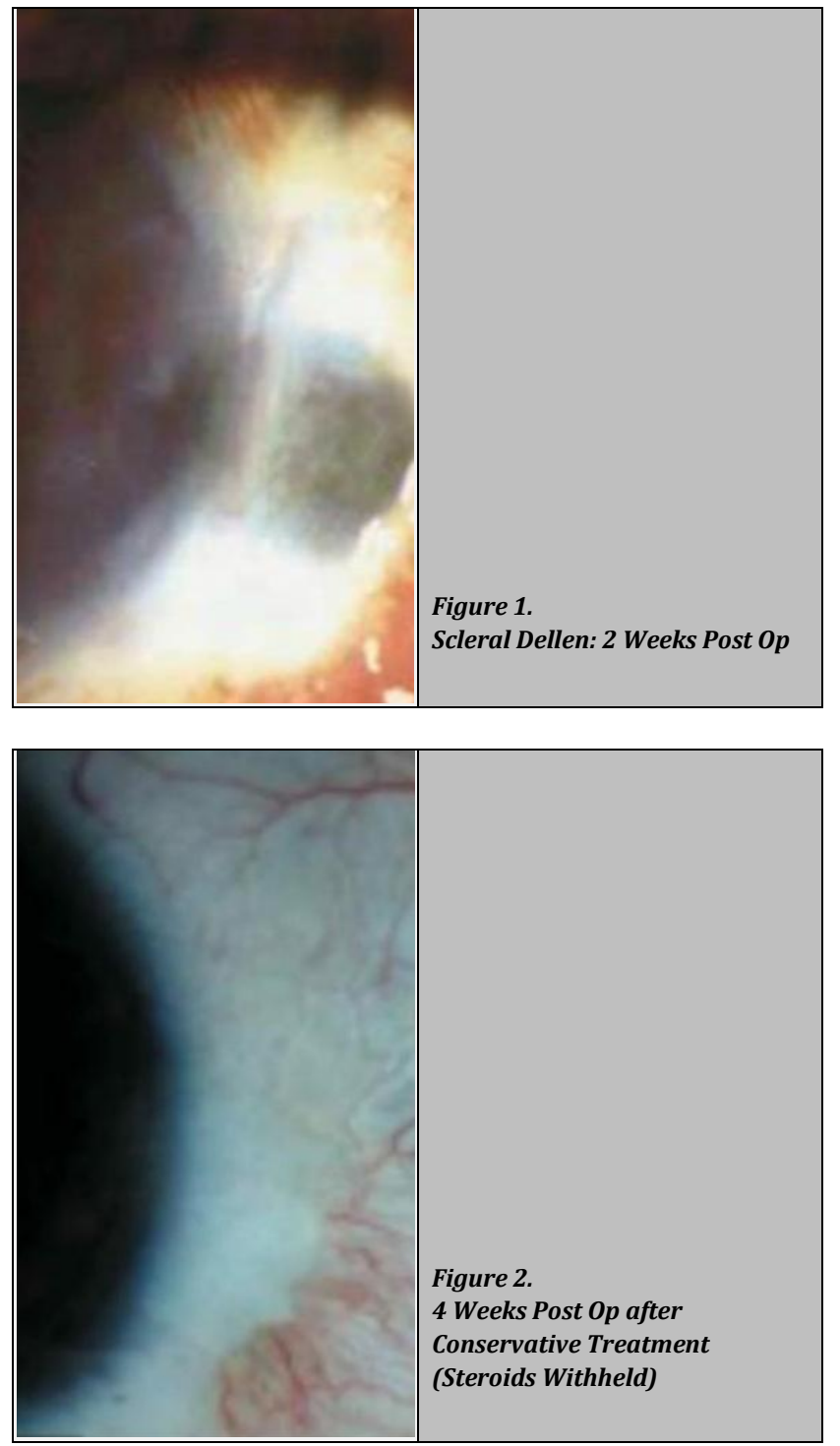

For the first postoperative week, no complaints or complications were noted. Combination therapy was given QID, \& TDS for 2 week. Two weeks after the surgery, patients came to OPD with complaints of slight discomfort in left eye since 2 days, $\&$ small dark area seen at the surgical site. There was no discharge \& on slit lamp examination there was no conjunctival reaction (conjunctival or ciliary congestion), corneal sensations were normal but there was scleral dellen with $2 \times 2 \mathrm{~mm}$ focal area of scleral thinning surrounded by oedematous conjunctiva (Figure 1). The thinned sclera appeared dry and the underlying blueish uvea was visible through the base of the lesion. Scleral dellen were diagnosed \& infectious cause of lesion was ruled out upon clinical finding. Due to financial constraints of the patient, conservative therapy was given in the form of topical lubricants eight times daily, Moxifloxacin $0.5 \%$ ointment, non-steroidal antiinflammatory eye drops Flurbiprofen $0.03 \%$ eye drops QID \& eye patching. The steroidal drop was withheld. On follow-up of patient after 1 week the scleral dellen had completely healed and after 4 weeks follow up, the earlier thinned sclera appeared regularly thick \& white in colour (Figure 2). There were no clinical signs of dry eye as the tear film breakup time and Schirmer's test were within normal limits. Our patient was non-diabetic so there were no other predisposing risk factors to ulceration such as Sjogren's syndrome, corneal pathology, corneal herpes, acne rosacea, scleritis, vasculitis or autoimmune process. There was no recurrence of pterygium after 3 months follow-up in the left eye. Patient was continued on tear film substitute \& after refraction testing appropriate spectacle prescription was given to the patient. Thus we identified individual patient challenges \& reduced avoidable blindness. This patient restored vision \& her quality of life improved.

\section{DISCUSSION}

Complication rate of pterygium surgery is 0 to $26 \% .^{4}$ Primary pterygium excision with or without adjunctive therapy has scleral dellen as a rare complication.5,6 Dellen are caused by interruptions of tear film and local dehydration of the cornea.? In Ophthalmic literature, dellen have been reported after pterygium surgery, large filtration blebs, dermoids, scleritis, episcleritis, scarring after extraocular muscle surgery or severe conjunctival chemosis. ${ }^{5}$ Denudated sclera is left for some time in the bare sclera technique of pterygium surgery, which theoretically may favour the onset of corneal dellen, if there is concomitant significant conjunctival oedema inhibiting normal tear distribution over the cornea \& reduced tear production. This was not the case in our patient. Our patient was healthy with no conditions predisposing to ulceration. Poor wound healing or reduced tear production as in case of Sjogren's syndrome, corneal pathology, corneal herpes, acne rosacea, scleritis, vasculitis was not present in our patient. Adjunctive substances like Mitomycin $C$ was not used to treat the patient but still there was onset of dellen postoperatively. Patients with pterygium might present with, reduction in tear film breakup time test \& instability of tear film layer, that worsens the tear fluid evaporation. Scleral thinning might be because of the postoperative use of steroid drops which causes scleral dellen. So when we shifted the patient from steroidal to non-steroidal anti-inflammatory eye drops, it enhanced scleral healing and topical lubricating drops enhanced hydration therapy with tear film substitutes, antibiotic ointment and eye patching rapidly improved scleral dellen.

Chen \& Noonan reported one case of scleral dellen treated with conjunctival flap \& regular antibiotic ointment as a complication of bare sclera excision without adjunctive therapy. Tsai et al reported a similar case as a complication of uneventful pterygium surgery performed with Mitomycin C and then treated with topical lubricant therapy. ${ }^{5}$ Recently Accorinti et al described a patient with corneal \& scleral dellen after a bare sclera technique without the use of antimetabolites and subsequent febrile episode. ${ }^{8}$ In our case we did not use any adjunctive substances example mitomycin $\mathrm{C}$ during pterygium excision however scleral dellen appeared 2 weeks after surgery.

Mitra et al proposed that, topical corticosteroids enhance collagenase \& inhibit collagen synthesis, which may have also contributed to scleral dellen formation. In our case after withdrawing the steroid which were started from the immediate postoperative period, and giving conservative therapy in the form of topical lubricants eight times daily, Moxifloxacin $0.5 \%$ ointment, non-steroidal anti-inflammatory eye drops Flurbiprofen $0.03 \%$ eye drops QID \& eye patching, the scleral dellen had completely healed after 1 week follow- 
up and after 4 weeks follow up, the earlier thinned sclera appeared regularly thick \& white in colour.

Scleral dellen is a rare but serious complication of an uneventful primary pterygium excision surgery using bare sclera technique, which improved with conservative treatment of topical lubricants eight times daily, Moxifloxacin ointment, non-steroidal anti-inflammatory eye drops Flurbiprofen QID \& eye patching.

\section{CONCLUSIONS}

Scleral dellen might occur even late after uneventful pterygium surgery performed without adjunctive therapies like Mitomycin C, excessive use of cautery or postoperative steroid eye drops. A conservative approach consisting of use of artificial tear, antibiotic ointment, nonsteroidal antiinflammatory drugs, lubricants \& patching are useful in the management of scleral dellen cases, thus improving livelihood \& quality of life of patient.

\section{REFERENCES}

[1] Kymionis GD, Plaka A, Kontadakis GA, et al. Treatment of corneal dellen with a large diameter soft contact lens. Cont Lens Anterior Eye 2011;34(6):290-2.

[2] Chen S, Noonan C. Scleral dellen complicating primary pterygium excision. Eye (Lond) 2000;14(Pt 1):100-1.

[3] Walkow T, Daniel J, Meyer $\mathrm{CH}$, et al. Long-term results after bare sclera pterygium resection with excimer smoothing and local application of mitomycin C. Cornea 2005;24(4):378-81.

[4] Mitra S, Ganesh A, Shenoy R. Scleral dellen complicating primary pterygium excision. Eye 2000;14(Pt 6):924-5.

[5] Tsai YY, Lin JM, Shy JD. Acute scleral thinning after pterygium excision with intraoperative mitomycin C: a case report of scleral dellen after bare sclera technique and review of the literature. Cornea 2002;21(2):227-9.

[6] Safianik B, Ben-Zion I, Garzozi HJ. Serious corneoscleral complications after pterygium excision with mitomycin $\mathrm{C}$. Br J Ophthalmol 2002;86(3):357-8.

[7] Fuchs E. Ueber dellen in der Cornea. Graefe's Arch Ophthalmol 1911;78:82-92.

[8] Accorinti M, Gilardi M, Giubilei M, et al. Corneal and scleral dellen after an uneventful pterygium surgery and a febrile episode. Case Rep Ophthalmol 2014;5(1):111-5. 